\title{
Functional analysis of Microcystis vertical migration: a dynamic model as a prospecting tool. II. Influence of mixing, thermal stratification and colony diameter on biomass production
}

\author{
Sophie Rabouille ${ }^{1,3, *}$, Marie-José Salençon ${ }^{2}$ \\ ${ }^{1}$ LEH, Université Paul Sabatier, Bat. IV R3, 31062 Toulouse cedex 4, France \\ ${ }^{2}$ Electricité de France, Recherche et Développement, LNHE/GHEO, 6 Quai Watier, 78401 Chatou cedex, France \\ ${ }^{3}$ Present address: Netherlands Institute of Ecology (NIOO-KNAW), Korringaweg 7, 4401 NT Yerseke, The Netherlands
}

\begin{abstract}
Yoyo is a deterministic model developed to represent the growth and vertical movement of Microcystis sp. colonies in the water column. Migration of colonies is represented in the model through the dynamics of carbon-reserve metabolism during photosynthesis and biosynthesis. It was used to quantify combined impacts of light, temperature and mixing on the growth and migration of colonies with different diameters. These 3 factors characterise a vertically non-homogeneous water column. Although conditions of simulation are schematic, they allow identification of situations in which the ability to regulate buoyancy gives Microcystis an advantage over non-mobile phytoplankton. Even if some vertical structures appear unfavourable for the exploitation of light energy, they nevertheless offer some advantages for the access to nutrients. Each diameter has particular benefits, and the increase in diameter observed throughout the year is probably an ecological adaptation to fluctuations in the environment at a seasonal scale.
\end{abstract}

KEY WORDS: Microcystis - Photosynthesis - Carbohydrates · Vertical migration - Hydrodynamics · Mixing zone $\cdot$ Thermocline $\cdot 1$-D mathematical model

Resale or republication not permitted without written consent of the publisher

\section{INTRODUCTION}

The cyanobacterium Microcystis sp. commonly thrives in eutrophic lakes and dammed reservoirs. Although this organism is a less efficient competitor regarding nutrients and has a lower specific growth rate than most phytoplankton species (Reynolds et al. 1987, Ibelings et al. 1994), it frequently dominates the phytoplankton community in summer. When exposed to low light intensities, cyanobacteria can increase their content of chlorophyll and other pigments, in order to prevent lower growth rates (Post et al. 1985, Rücker \& Kohl 1994). This adaptation to low light intensities is known to facilitate the succession from green algae or diatoms to cyanobacteria in summer, when high phytoplankton biomasses limit the penetration of light into the water column. Moreover, Micro- cystis regulates its vertical position in the water column through fluctuations of its intracellular carbohydrate reserves, in relation to its photosynthetic activity. This feature is assumed to facilitate its development in stratified environments (Thomas \& Walsby 1985, 1986, Van Rijn \& Shilo 1985, Kromkamp et al. 1988, Deacon \& Walsby 1990, Konopka et al. 1993). The ability of some cyanobacteria to be buoyant requires them to be lighter and larger than other phytoplankton species. Gas vesicles provide cells with buoyancy, reducing their density. Moreover, the aggregation of cells into colonies (spherical in Microcystis) results in a lower surface:volume ratio, which is favourable to buoyancy, but unfavourable to the uptake rate of nutrients.

In order to represent the migratory behaviour of Microcystis, a model called Yoyo has been developed 
(Rabouille et al. 2003). It simulates, at a daily scale, changes in growth and vertical migration of colonies due to the dynamics of the metabolism of carbon reserves during photosynthesis and biosynthesis. A previous analysis of this model under permanent conditions of light and temperature in a non-turbulent water column permitted us: (1) to independently explore the influence of light and of temperature on the migration pattern and (2) to test the variability of these migratory responses as a function of colony diameter (Rabouille et al. 2005). In the present study, we have analysed the combined influence of light, temperature and mixing on the growth and migration of colonies with different diameters. Most of the simulated diameters were chosen according to field observations in the Grangent reservoir (Loire, France) and are thus representative of colony sizes actually found in this reservoir throughout spring and summer. The largest diameters, though much less common, were nevertheless tested in the model, in order to cover the largest possible range of colony sizes and to estimate the behaviour of such colonies. Present simulations are not intended to represent realistic conditions. They are part of a model sensitivity analysis with regard to specific forcing conditions.

\section{BRIEF DESCRIPTION OF THE MODEL}

YoYo is a deterministic model (1-dimensional vertical) intended to represent the growth and vertical movements of a population of Microcystis sp. colonies in the water column of a lake. A complete description of the model structure is given in Rabouille et al. (2005); here, we briefly outline the main components and relations. The growth model is based on a mass balance. It focuses on the dynamics of intracellular carbon, through both mechanisms of carbon fixation (photosynthesis) and biomass synthesis, resulting in migration movements. The model thus accounts for changes in colony density and growth; vertical migration is simulated as a result of density fluctuations (Visser et al. 1997). Colonies are described with 2 different state variables: the carbohydrate ballast $C$ ( $\mu \mathrm{g} \mathrm{C}^{-1}$ ), which represents the carbon fixed by photosynthesis and stored as carbohydrates in cells, and the cell material $M\left(\mu \mathrm{g} \mathrm{C}^{-1}\right)$, which is the cell biomass without carbohydrate reserves, also expressed in carbon units. Cell cohesion within colonies is ensured by mucilage, included in the cell material, which represents a constant proportion over time (75\% in the model). Gas vesicle proteins (Vesic [ $\mu \mathrm{g} \mathrm{C}$ $\left.\mathrm{l}^{-1}\right]$ ) are considered to be a constant fraction $\mathrm{Vp}(\mathrm{Vp}=$ 0.08) of cell material $M$. Fluctuations of the $C$ reserve lead to density changes in colonies that are reflected by the ratio between the variables $C$ and $M$ (C:M ratio). Hydrodynamic conditions (thermal profile, thermocline depth, depth of the well-mixed layer, irradiance, extinction coefficient) are introduced as forcing variables. The colony diameter does not change with growth.

The carbon fixation process simulated in the model regroups the photochemical phase of photosynthesis and the reduction of inorganic carbon dissolved in the water as carbohydrates in cells. It depends on light intensity, with an optimal value at $I_{\text {opt }}=250 \mathrm{~W} \mathrm{~m}^{-2}$ (expressed as the total spectrum, thus $\sim 539 \mu \mathrm{mol}$ photons $\mathrm{m}^{-2} \mathrm{~s}^{-1}$ of photosynthetically active radiation, PAR), and takes into account the photoinhibition of this process through a lowering of the carbon fixation rate under high light intensities (from Peeters \& Eilers 1978). This value is comparable to the one used in the new SCUM model (Howard 2001, in which the maximum photosynthetic rate at $20^{\circ} \mathrm{C}$ is obtained at $753 \mu \mathrm{mol}$ photons $\mathrm{m}^{-2} \mathrm{~s}^{-1}$ ). We did not model the light attenuation within colonies as a function of their diameter. $C$ reserve filling is assumed to be independent of temperature. Biosynthesis is modelled as the production of cell material $(M)$ from carbon reserves $(C)$ and nutrients. It is described through the rate of carbon transfer from $C$ to $M$, and represents growth activity. It does not require light and can thus occur night and day, whenever $C$ reserves are available. This synthesis is influenced by temperature, according to the limitation function proposed by Parker (1974), adjusted based on data from the literature (Reynolds \& Rogers 1976, Thomas \& Walsby 1986, Visser 1995). The respiration process involves carbohydrate degradation, which enables the generation of energy required for maintenance and metabolic activity; it is expressed as a carbon loss. Finally, the carbon excretion rate is represented in the model as a loss of cell material $M$. As for biosynthesis, both respiration and excretion depend on the environmental temperature.

Under favourable environmental conditions, the rate of biomass synthesis is proportional to the amount of stored carbon. Environmental conditions modulate this flux and finally determine the rate of $C$ reserve decrease. The ballast dynamics result from the imbalance between the 2 fluxes: carbon input (fixation) and use (biosynthesis, respiration, excretion).

\section{SIMULATIONS}

In natural environments, external forcings on lakes and reservoirs (wind, cooling, inflows, outflows, etc.) result in the initiation of fluid movement (turbulence, internal waves, upwellings, density currents, etc.). 
Thus, any apparently calm water body, such as a lake, is continuously animated with complex water circulations; these movements, linked to its topography, to meteorological conditions and to the management of hydraulic installations, continually determine the thermal structure of the system. Such movements are associated with time scales from minutes to several hours, and constitute a highly variable environment for the phytoplankton (Spigel \& Imberger 1987, Salençon \& Thébault 1997).

The vertical structure of the water column, due to surface mixing, determines the phytoplankton environment, as it influences the distribution of phytoplankton within the vertical gradients of light and temperature. The possible ecological advantage offered by the mobility of Microcystis is tackled here in terms of the amount of light energy colonies can exploit. The 3 following parameters characterise the water column (Fig. 1):

(1) The mixed layer, the depth of which is $Z_{m}$, represents the zone in which organisms are entrained by

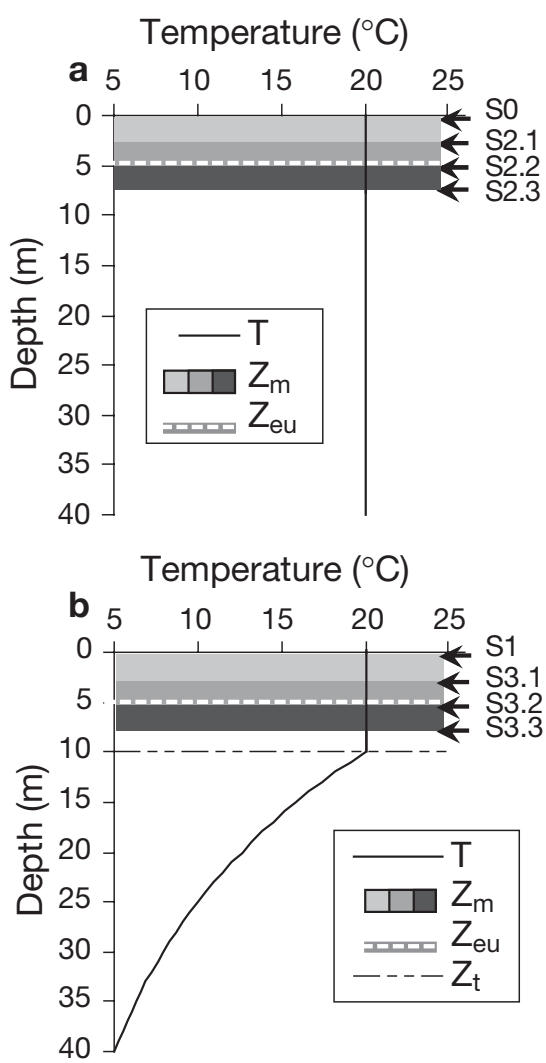

Fig. 1. Schematic representation of vertical structures simulated in the different scenarios: (a) isothermal water column and (b) stratified water column ( $T$ : temperature; $Z_{\mathrm{m}}$ : depth of the mixing zone; $Z_{\text {eu }}$ : depth of the euphotic zone; $Z_{\mathrm{t}}$ : depth of the thermocline). Each depth of $Z_{\mathrm{m}}$ determines a scenario, the designation of which indicated on the right of the bars upper-layer turbulences and maintained in homogeneous suspension. It represents a transitory thermocline which is very reactive to diurnal fluctuations in surface conditions. In simulations, 4 mixing depths were explored: $Z_{\mathrm{m}}=0 \mathrm{~m}$ (no mixing), $2.5 \mathrm{~m}, 5 \mathrm{~m}$ and $7.5 \mathrm{~m}$

(2) The epilimnion, the depth of which is $Z_{t}$, defines the seasonal thermocline characterised by a steep temperature gradient. From the surface to $Z_{\mathrm{t}}$, temperature is almost homogeneous (and set at $20^{\circ} \mathrm{C}$ in the simulations); below $Z_{\mathrm{t}}$, temperature exponentially decreases down to the bottom $\left(5^{\circ} \mathrm{C}\right)$. In all the present simulations, $Z_{\mathrm{t}}=10 \mathrm{~m}$. Note that $Z_{\mathrm{m}}$ and $Z_{\mathrm{t}}$ are 2 distinct entities. The settlement of the transient mixed layer $Z_{\mathrm{m}}$ results from a mixing process, in which surface kinetic energy produced by hourly fluctuating meteorological forcing is transformed into potential energy: $Z_{\mathrm{m}}$ is a diurnal thermocline. The seasonal thermocline $Z_{\mathrm{t}}$ traces, in any stratified lake, the maximum depth that surface turbulence can reach, in spring and summer, during the alternation of surface mixing and warming processes. One could consider $Z_{\mathrm{t}}$ to be a fossil imprint of spring diurnal thermoclines in the thermal profile. It remains stable during summer, and then the following relation is always true: $Z_{\mathrm{m}} \leq Z_{\mathrm{t}}$. During autumn cooling, $Z_{\mathrm{m}}$ joins $Z_{\mathrm{t}}$ and deepens until the overturn. Conditions investigated in this paper are representative of this reality; the mixed zone $Z_{\mathrm{m}}$ simulated by the model is the transient diurnal thermocline (i.e. from a turbulent point of view) and $Z_{\mathrm{t}}$ is the seasonal thermocline, with its sharp temperature gradient in the lower part of the epilimnion (i.e. from a thermal point of view).

(3) $Z_{\text {eu }}$ is the depth of the euphotic zone. Its lower limit is defined as the depth where photosynthesis just compensates for the losses due to respiration (compensation depth). Below $Z_{\text {eu }}$ losses due to respiration are larger than the gain through photosynthesis. In all simulations, $Z_{\text {eu }}$ is kept constant at $5 \mathrm{~m}$, so that results remain comparable; the extinction coefficient is constant, and light extinction due to biomass is not taken into account.

These 3 layers do not vary during individual simulations. We simulated different typical configurations of these layers in order to distinguish the vertical structures most favourable for Microcystis development and to highlight situations in which migration provides an advantage for the growth of Microcystis. A daily sine regime of irradiance was applied with conditions of a sunny summer day with a clear sky: the maximum intensity was $650 \mathrm{~W} \mathrm{~m}^{-2}$ (total spectrum, equivalent to $1401 \mu \mathrm{mol}$ photons $\mathrm{m}^{-2} \mathrm{~s}^{-1}$ PAR) at noon, with a photoperiod of $16 \mathrm{~h}$ light: $8 \mathrm{~h}$ dark. S0 is the scenario described by Rabouille et al. (2005), and was taken as the reference scenario. 


\section{RESULTS}

When simulations are run, the biomass is evenly distributed over the lake at Time 0 . A biomass peak forms as colonies migrate and regroup. We locate the layer in which the biomass concentration is the highest: this maximum concentration of the peak is representative of the population behaviour. In figures showing the vertical migration of colonies over time, we traced the changes in depth of this maximum concentration. A regular, oscillating migration appears; depending on environmental conditions and on colony size, this oscillation can present different periodicities (i.e. the duration of 1 migration cycle). We called minimum (or maximum) depth of biomass or colonies the shallowest (or deepest) depth reached by the peak during migration cycles.
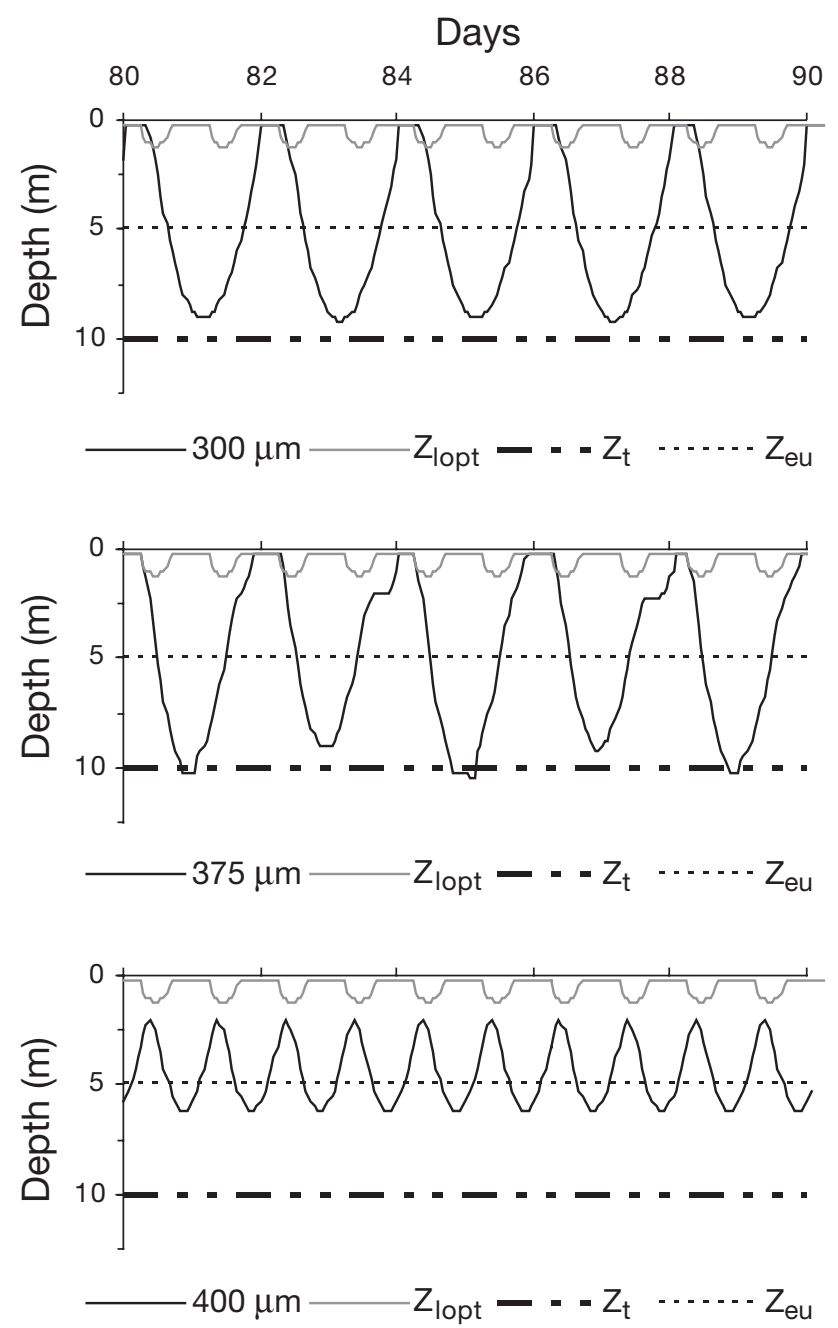

Thermocline at $10 \mathrm{~m}$, non-turbulent epilimnion (Scenario S1, $Z_{\mathrm{t}}=10 \mathrm{~m}, Z_{\mathrm{m}}=\mathbf{0} \mathrm{m}$ )

In Scenario $\mathrm{S} 1$ the only difference compared to $\mathrm{S} 0$ is the thermal stratification. For all colonies, results are identical to S0, as long as the migration depth does not reach $Z_{\mathrm{t}}=10 \mathrm{~m}$.

Among small colonies, the highest biomass is always obtained for $250 \mu \mathrm{m}$, when the periodicity is $48 \mathrm{~h}$ and the biomass peak reaches the surface in early morning without staying there. Up to $300 \mu \mathrm{m}$, cycles are regular. Crossing of the thermocline $(350 \mu \mathrm{m})$ induces a bimodal pattern of migration: colonies only sink below $Z_{\mathrm{t}}$ in 1 period out of 2 (Fig. 2). Indeed, the lower temperature slows down biosynthesis, increasing the time needed to float back to the surface. Colonies come back into the euphotic zone at the end of the day, store
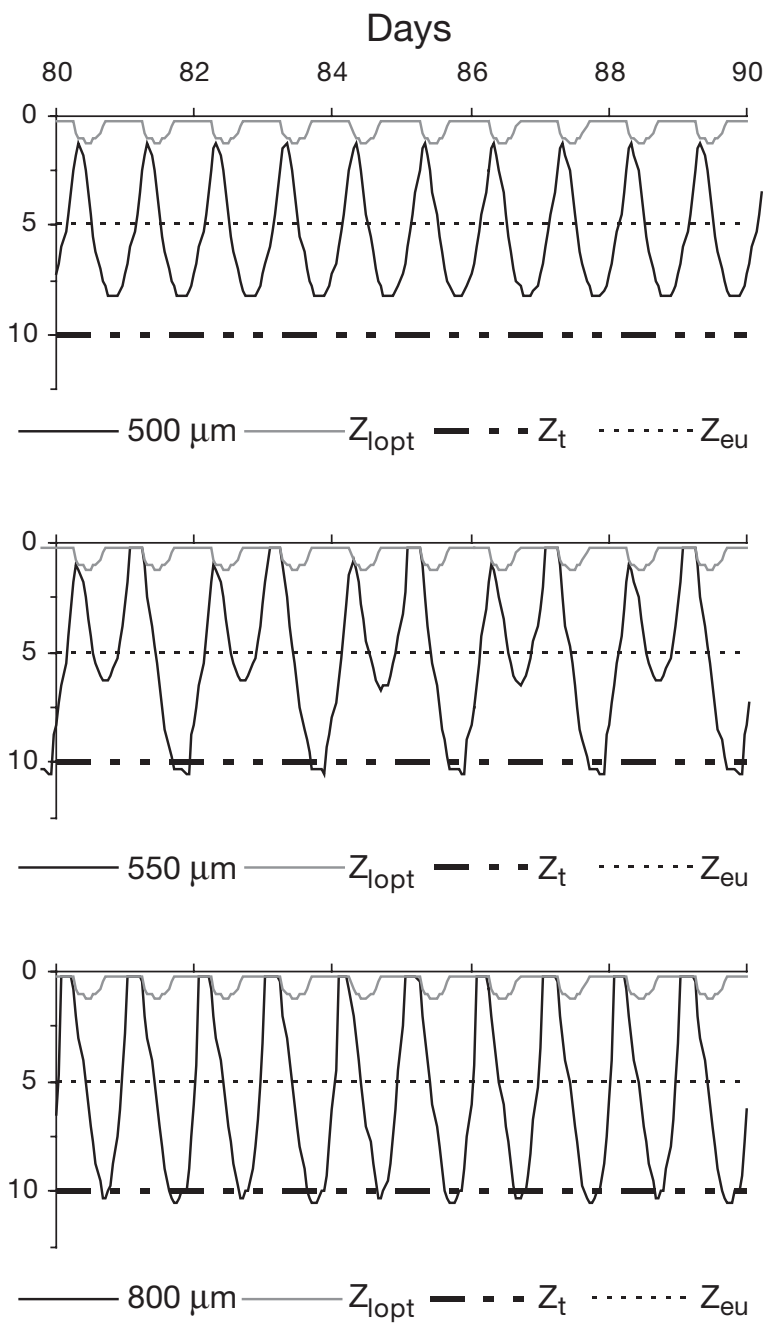

Fig. 2. Scenario $\mathrm{S} 1\left(Z_{\mathrm{t}}=10 \mathrm{~m}, Z_{\mathrm{m}}=0 \mathrm{~m}\right)$. Vertical migration of 300, 375, $400 \mu \mathrm{m}$ colonies, then 500, 550, $800 \mu \mathrm{m}$ colonies. The vertical position of the peak (point where biomass concentration is the highest) is traced through time from Day 80 until Day 90 ( $Z_{\text {Iopt }}$ : depth at which the penetrating irradiance equals the optimum irradiance for carbon fixation; $Z_{t}$ : depth of the thermocline; $Z_{\text {eu }}$ : depth of the euphotic zone) 
a little carbon and stay at the surface longer at night, where they go on consuming their carbohydrate reserves (the high temperature allows this consumption). After sunrise, they can store some carbon again, but sinking begins later than when their nocturnal stay at the surface is short, as they have to wait until they reach the proper $C$ to $M$ ratio (C:M) at which downward migration will set in. When colonies sink, they encounter zones in which the irradiance is too high to allow the same storage of carbon as is possible when they begin to sink earlier with a higher $C: M$. Their lighter carbon reserves do not allow them to sink deep enough to cross $Z_{\mathrm{t}}$ again. They stay at their maximum depth for a shorter time (temperature there is warmer than below $Z_{\mathrm{t}}$ ) and join $Z_{\text {eu }}$ early enough to store carbon and thus delay their arrival at the surface. Thus, at sunrise, their reserves are more plentiful than during the previous cycle; they begin to sediment earlier and to store more carbon, as they encounter more optimal light conditions during their descent into $Z_{\text {eu }}$. In these cases of bimodal migration, colonies exploit the light less efficiently, leading to a lower produced biomass. While diameter increases, the velocities of movement increase too, and the return to $Z_{\text {eu }}$ occurs early enough to trigger another complete cycle and to re-establish $24 \mathrm{~h}$ periodicity. This transition is observed between 375 and $400 \mu \mathrm{m}$ (Fig. 2).

From $400 \mu \mathrm{m}, \mathrm{S} 0$ and S1 scenarios display similar results until colonies cross $Z_{\mathrm{t}}$, between 500 and $550 \mu \mathrm{m}$ (Fig. 3). From $550 \mu \mathrm{m}$ colonies, the migration mode turns to bimodal again, with a lower biomass, as previously described. From $800 \mu \mathrm{m}$ migrations become regular again. A slight increase in the biomass produced at $800 \mu \mathrm{m}$ occurs due to more efficient exploitation of light (Figs. 2 \& 3). As observed in S0, S1 shows that the larger the diameter, the faster the colony migration is and the less they exploit the light-intense layers.

As soon as colonies reach the strong thermal gradient zone, the lower temperature slows down the consumption of carbon and thus the upward movement of colonies. When colonies stay below $Z_{\text {eu }}$ longer, they come back to the surface slower and have smaller carbon reserves; they exploit the light less efficiently. Growth is then limited 2-fold: directly, through the effect of temperature on biosynthesis, and indirectly, via migration that no longer allows the optimal use of light in layers near the surface.

\section{Simulations with a mixing layer}

Due to mixing, the biomass concentration is regularly (at each time step) and evenly distributed over $Z_{\mathrm{m}}$. Colonies nevertheless experience different light conditions during each time step, depending on their loca-
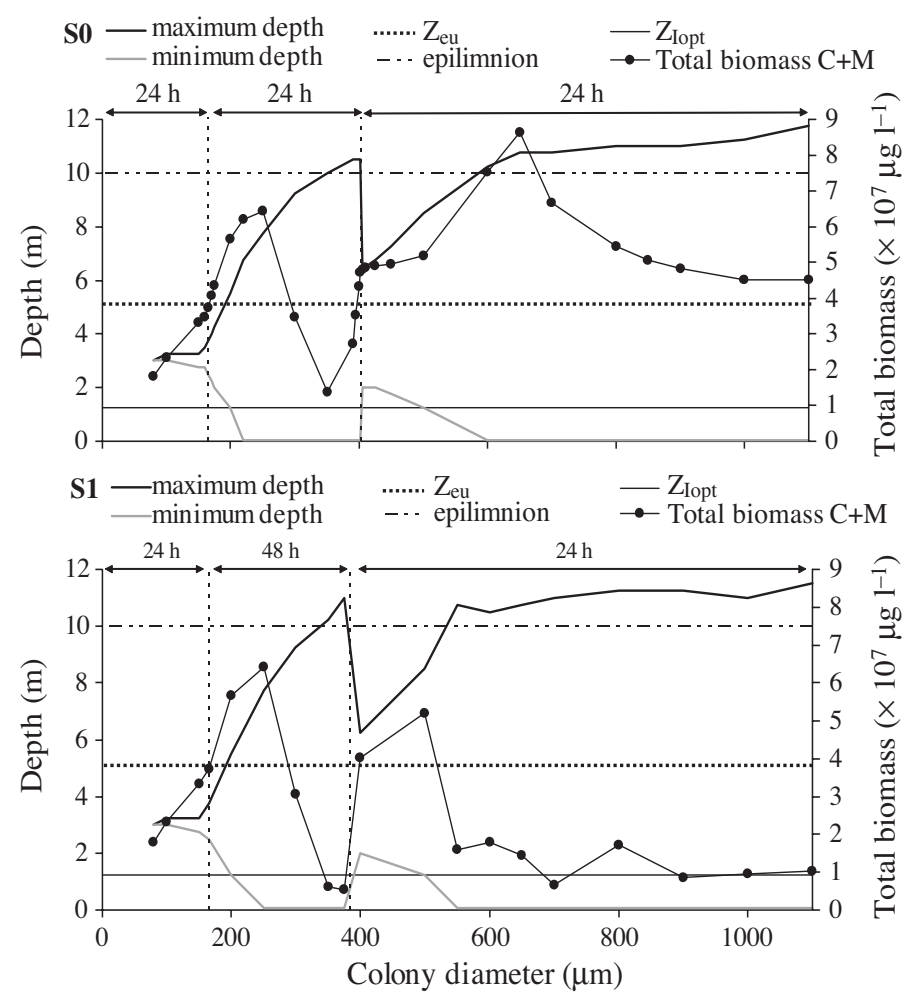

Fig. 3. Comparison of Scenarios $\mathrm{S} 0\left(Z_{\mathrm{t}}=0 \mathrm{~m}, Z_{\mathrm{m}}=0 \mathrm{~m}\right)$ and S1 $\left(Z_{\mathrm{t}}=10 \mathrm{~m}, Z_{\mathrm{m}}=0 \mathrm{~m}\right)$. Changes in amplitude of migration and biomass observed at the end of the simulation, according to the colony size. The migration amplitude is formed by the minimum and maximum depths of migration $\left(Z_{\text {Iopt }}\right.$ at which the penetrating irradiance equals the optimum irradiance for carbon fixation; $Z_{\text {eu }}$ : depth of the euphotic zone). Horizontal arrows cover the range of diameters that present the same periodicity of migration ( 24 or $48 \mathrm{~h}$ )

tion within $Z_{\mathrm{m}}$, resulting in different densities and growth. The model then calculates the average biomass concentration and density of the biomass present in $Z_{\mathrm{m}}$ and redistributes this average to each layer of $Z_{\mathrm{m}}$.

Mixing in a non-thermally stratified water column (S2 scenarios: $Z_{\mathrm{t}}=0 \mathrm{~m}, Z_{\mathrm{m}}$ )

Mixing events lead to inefficient colony migration over the entire $Z_{\mathrm{m}}$. Under these conditions, when (part of) the biomass migrates upwards into the mixing zone $Z_{\mathrm{m}}$, it is distributed homogeneously throughout $Z_{\mathrm{m}}$. When plotting the biomass curves, we considered it was at the surface. Mixing in the water column modifies the 24 or $48 \mathrm{~h}$ dynamics previously observed in a stable water column (S0).

Scenario $S 2.1: Z_{m}=2.5 \mathrm{~m}$. In this scenario, the mixing zone is shallower than the euphotic zone $\left(Z_{\mathrm{m}}<\right.$ $Z_{\text {eu }}$ ). Migratory cycles of 24 and $48 \mathrm{~h}$ are not modified. 
The behaviour of colonies remains unchanged as long as their minimum depth is shallower than $Z_{\mathrm{m}}$, which is true in colonies from 80 to $200 \mu \mathrm{m}$. However, it should be noted that the produced biomass is higher than in S0 (about twice as high). Indeed, even if the biomass peak oscillates below $Z_{\mathrm{m}}$, it remains close to it. Some of the colonies that float up are entrained in $Z_{\mathrm{m}}$, and thus produce a higher biomass, as they benefit from more favourable light conditions than those found in S0. Afterwards, a biomass explosion is observed for $200 \mu \mathrm{m}$ colonies, the first diameter for which the biomass peak penetrates into $Z_{\mathrm{m}}$ and is entrained in layers where the light intensity is higher (Fig. 4). The biomass is 4 times as high as that produced in S0. With increasing diameters and as long as the migration periodicity is $48 \mathrm{~h}$, the faster access to surface layers due to mixing does not increase the access to light, as colonies move upwards during the night (Fig. 5). Produced biomasses are similar to those in $\mathrm{S} 0$.

The return to $24 \mathrm{~h}$ periodicity occurs for diameters $\geq 375 \mu \mathrm{m}$. The peak that floated up above $2.5 \mathrm{~m}$ in S0 is now entrained in $Z_{\mathrm{m}}$, and the biomass is slightly higher than in S0. Large colonies (diameter $\varnothing \geq 600 \mu \mathrm{m}$ ), which floated back to the surface in S0, return here faster to $Z_{\text {eu }}$ and $Z_{\mathrm{m}}$. However, mixing does not allow colonies to stay at the surface, where they could exploit the light from sunrise due to their buoyancy, as they did in S0. Maintained in suspension in $Z_{\mathrm{m}}$, where they globally receive a lower irradiance, colonies store less carbon, sink less deep and thus float back into $Z_{\mathrm{m}}$ faster, where the duration of the nocturnal stay rapidly increases with diameter. This sequence offsets the benefits that large colonies could gain from a deep migration and leads to a noticeable biomass decrease for colonies $\geq 600 \mu \mathrm{m}$.

Scenario S2.2: $Z_{\mathrm{m}}=5 \mathrm{~m}$. In this scenario, mixing keeps colonies in the euphotic zone $\left(Z_{\mathrm{m}}=Z_{\text {eu }}\right)$. The original $24 \mathrm{~h}$ periodicity is replaced by $48 \mathrm{~h}$ periodicity.

Small colonies $(\varnothing<100 \mu \mathrm{m})$, which do not migrate a lot in $\mathrm{S} 0$, are trapped in $Z_{\mathrm{m}}$. They now have access to a larger range of light intensities; their biomass thus explodes (200 times as high as in S0 for the $100 \mu \mathrm{m}$ colonies). From $100 \mu \mathrm{m}$, the velocity becomes high enough to allow colonies to sink below $Z_{\mathrm{m}}$, with $48 \mathrm{~h}$ periodicity, since they move quite slowly (Fig. 6). As soon as migration is below $Z_{\mathrm{m}}$, biomass immediately decreases, as irradiance is lower. The transition to $24 \mathrm{~h}$ periodicity is observed between 350 and $375 \mu \mathrm{m}$, with an irregular cycle. The increase in velocity occurring with an increase in diameter allows the biomass peak to return to $Z_{\mathrm{m}}$ earlier and earlier. While dispersed in $Z_{\mathrm{m}}$ (which here matches $Z_{\text {eu }}$ ), colonies fix enough carbon to sink out of $Z_{\mathrm{m}}$ the following night, before returning at sunrise. For colonies around $400 \mu \mathrm{m}$, the biomass peak returns to
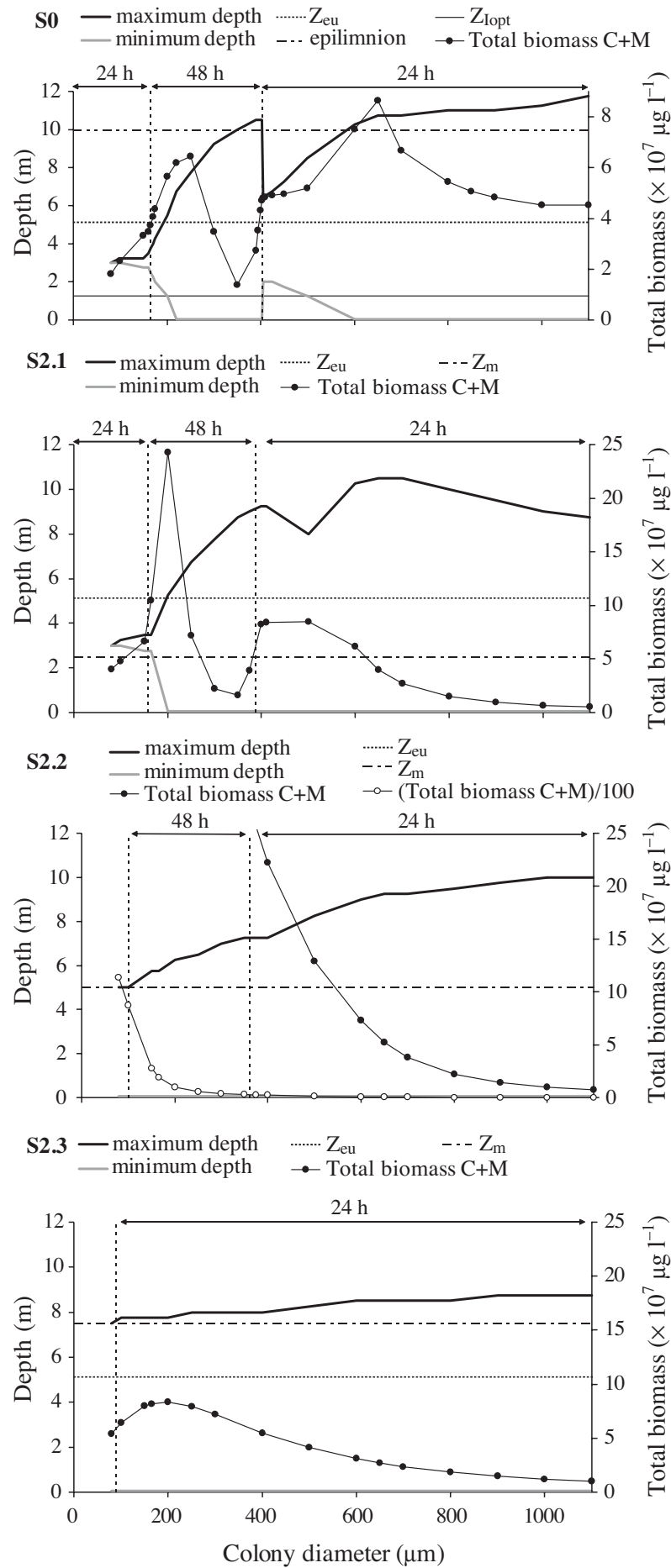

Fig. 4. Comparison of Scenarios $\mathrm{S} 0\left(Z_{\mathrm{t}}=0 \mathrm{~m}, Z_{\mathrm{m}}=0 \mathrm{~m}\right)$, $\mathrm{S} 2.1\left(Z_{\mathrm{m}}=2.5 \mathrm{~m}\right), \mathrm{S} 2.2\left(Z_{\mathrm{m}}=5 \mathrm{~m}\right)$ and $\mathrm{S} 2.3\left(Z_{\mathrm{m}}=7.5 \mathrm{~m}\right)$. Changes in amplitude of migration and biomass observed at the end of the simulation, according to the colony size. The migration amplitude is formed by the minimum and maximum depths of migration $\left(Z_{\text {Iopt }}\right.$ : at which the penetrating irradiance equals the optimum irradiance for carbon fixation; $Z_{\mathrm{eu}}$ : depth of the euphotic zone; $Z_{\mathrm{m}}$ : depth of the mixing zone). Horizontal arrows cover the range of diameters that present the same periodicity of migration (24 or $48 \mathrm{~h}$ ) 

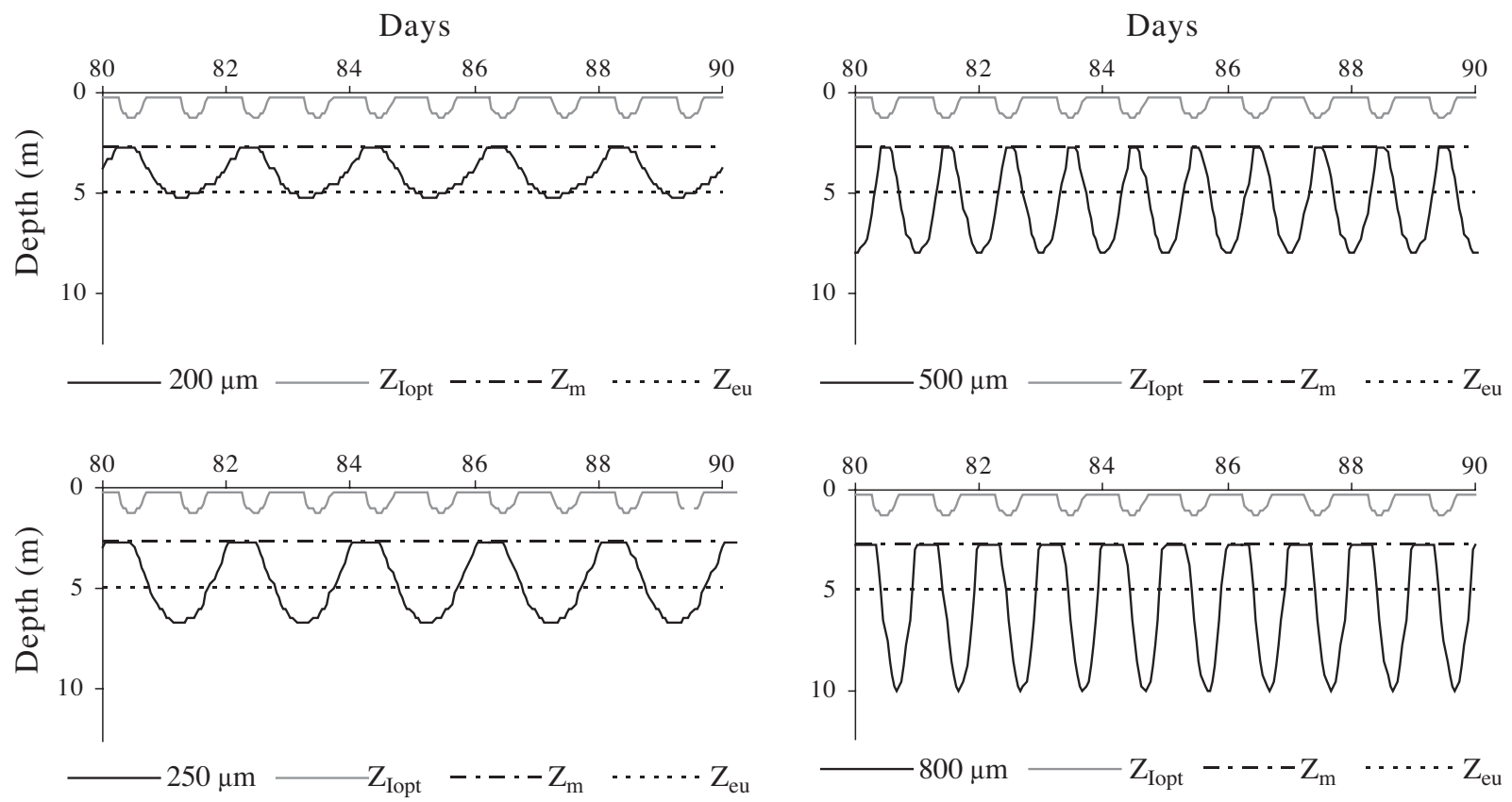

Fig. 5. Scenario $\mathrm{S} 2.1\left(Z_{\mathrm{t}}=0 \mathrm{~m}, Z_{\mathrm{m}}=2.5 \mathrm{~m}\right)$. Vertical migration of 200, 250, 500 and $800 \mu \mathrm{m}$ colonies from Day 80 until Day 90. The vertical position of the biomass maximum is traced through time $\left(Z_{\text {Iopt }}\right.$ : depth at which the penetrating irradiance equals the optimum irradiance for carbon fixation; $Z_{\mathrm{m}}$ : depth of the mixing zone; $Z_{\text {eu }}$ : depth of the euphotic zone)
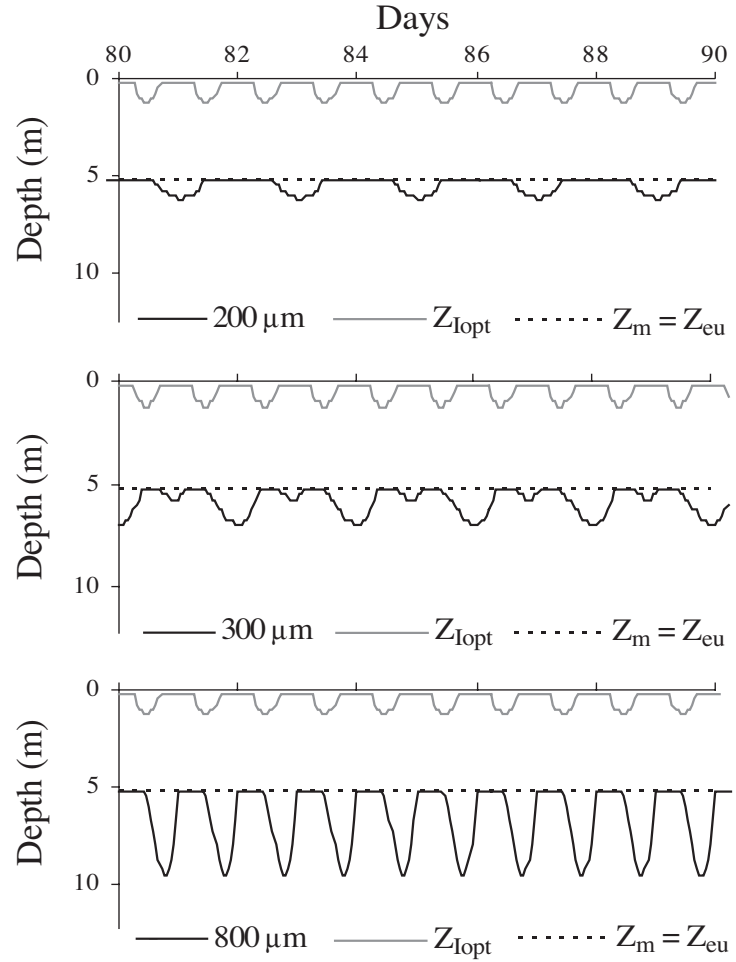

Fig. 6. Scenario $\mathrm{S} 2.2\left(Z_{\mathrm{t}}=0 \mathrm{~m}, Z_{\mathrm{m}}=5 \mathrm{~m}\right)$. Vertical migration of 200, 300 and $800 \mu \mathrm{m}$ colonies from Day 80 until Day 90. The vertical position of the biomass maximum is traced through time $\left(Z_{\text {Iopt }}\right.$ : depth at which the penetrating irradiance equals the optimum irradiance for carbon fixation; $Z_{\mathrm{m}}$ : depth of the mixing zone; $Z_{\text {eu }}$ : depth of the euphotic zone)
$Z_{\mathrm{m}}$ in the middle of the day, leading to an important period of biomass production. The larger the diameter, the more colonies promptly react to light exposure. The biomass peak penetrates $Z_{\mathrm{m}}$ earlier, and sometimes even during the night; migration and light cycles become synchronised. However, time spent in the light-intense zone is reduced, and, thus, biomass decreases for large diameters, as in S2.1.

Scenario S2.3: $Z_{m}=7.5 \mathrm{~m}$. In this scenario, mixing entrains colonies below the euphotic zone $\left(Z_{\mathrm{m}}>Z_{\mathrm{eu}}\right)$; the irradiance received in $Z_{\mathrm{m}}$ is much lower than in the previous scenario (S2.2) (Fig. 7).

The $80 \mu \mathrm{m}$ colonies cannot migrate beyond $Z_{\mathrm{m}}$ i they passively undergo turbulence and produce a biomass equivalent to that in S0. From $100 \mu \mathrm{m}$ and above, some colonies can escape $Z_{\mathrm{m}}$, but remain in the layer just below the mixing zone, unlike colonies in S2.2 that sink deeper. Thus, there appears to be a difference in the migration patterns for identical colonies between these 2 scenarios. The observed discrepancy results from a more efficient use of light in S2.2, since $Z_{\mathrm{eu}}=Z_{\mathrm{m}}$, leading to a higher $C: M$ ratio than in S2.3. As long as velocities are low enough, the biomass peak shows a stationary location below $Z_{\mathrm{m}}$ and an exchange of part of the biomass occurs from and to $Z_{\mathrm{m}}(\varnothing<200 \mu \mathrm{m})$; biomass increases with diameter. When the biomass peak sinks deeper, the total biomass decreases, since the global irradiance received during 1 migration cycle is lower. The $48 \mathrm{~h}$ 

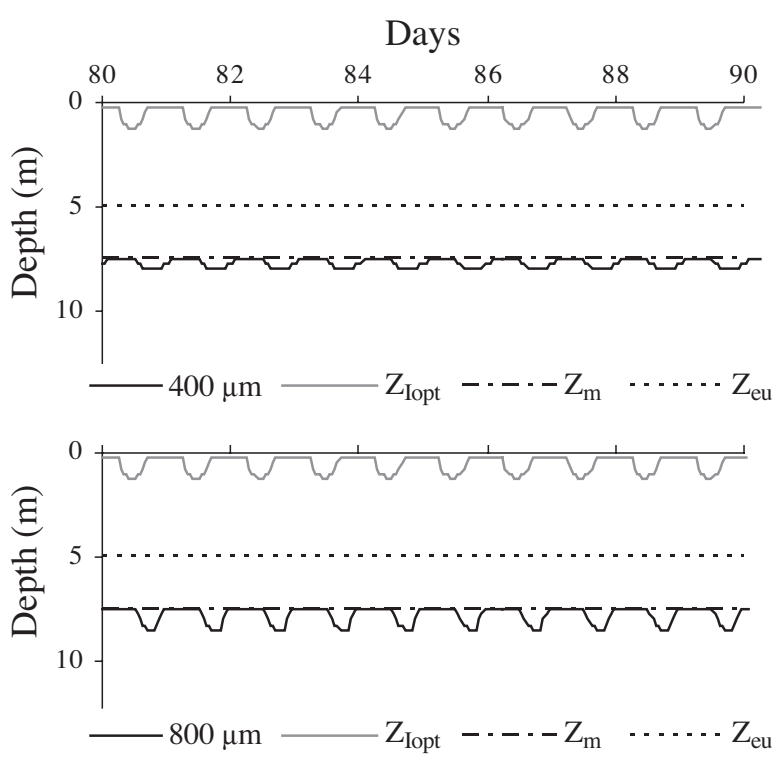

Fig. 7. Scenario S2.3 $\left(Z_{\mathrm{t}}=0 \mathrm{~m}, Z_{\mathrm{m}}=7.5 \mathrm{~m}\right)$. Vertical migration of 400 and $800 \mu \mathrm{m}$ colonies from Day 80 until Day 90. The vertical position of the biomass maximum is traced through time $\left(Z_{\text {Iopt }}\right.$ : depth at which the penetrating irradiance equals the optimum irradiance for carbon fixation; $Z_{\mathrm{m}}$ : depth of the mixing zone; $Z_{\mathrm{eu}}$ : depth of the euphotic zone)

migration cycle is linked to the duration of the way back to the surface; it cannot appear when the mixed layer is so deep. Only the $24 \mathrm{~h}$ cycle can be observed here.

Mixing in a thermally stratified water column (S3 scenarios: $Z_{\mathrm{t}}=10 \mathrm{~m}, Z_{\mathrm{m}}$ )

S3 scenarios are based on the same mixing events as $\mathrm{S} 2$; a thermal stratification at $10 \mathrm{~m}$ depth is added. Results only differ from S2 when the maximum depth of migration penetrates into the steep thermal gradient zone. This only occurs in S3.1 $\left(Z_{\mathrm{m}}=2.5 \mathrm{~m}\right)$ for colonies from 600 to $800 \mu \mathrm{m}$ (Fig. 8).

As already observed in $\mathrm{S} 1$, the stay in $Z_{\mathrm{t}}$ slows down the ascent and triggers the appearance of a bimodal rhythm of migration in colonies from 600 to $700 \mu \mathrm{m}$ (Fig. 9). The growth of colonies that penetrate the thermal gradient is lower, and the mean biomass produced is lower than in S2.1 (Fig. 8).

\section{DISCUSSION}

Migration of Microcystis colonies appears to be an auto-regulated system designed to use light more efficiently. Globally, during their migration cycle, colonies
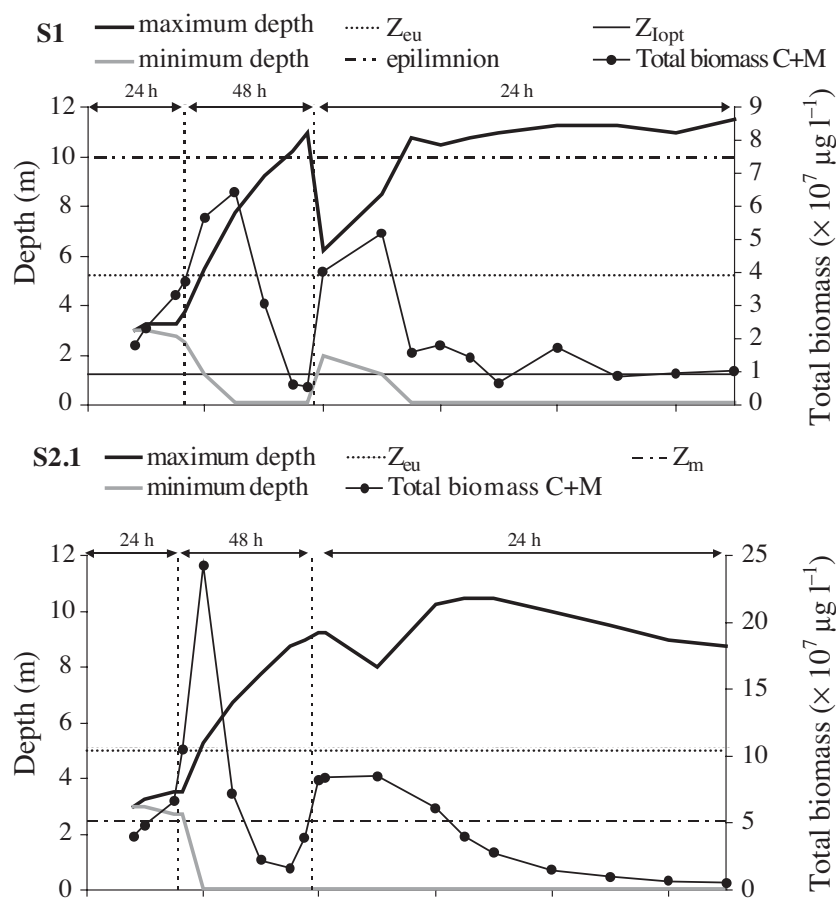

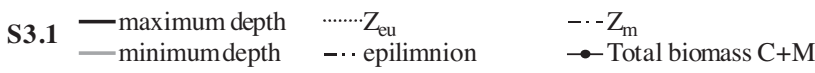

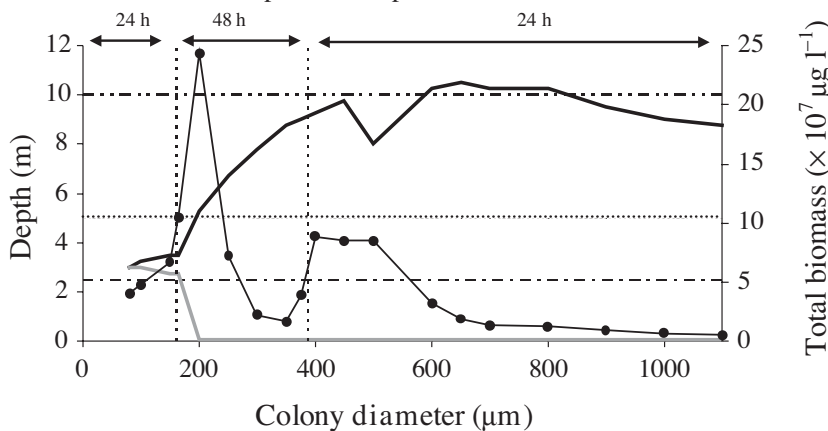

Fig. 8. Comparison of Scenarios $\mathrm{S} 1\left(Z_{\mathrm{t}}=10 \mathrm{~m}, Z_{\mathrm{m}}=0 \mathrm{~m}\right)$, $\mathrm{S} 2.1\left(Z_{\mathrm{t}}=0 \mathrm{~m}, Z_{\mathrm{m}}=2.5 \mathrm{~m}\right)$ and $\mathrm{S} 3.1\left(Z_{\mathrm{t}}=10 \mathrm{~m}, Z_{\mathrm{m}}=\right.$ $2.5 \mathrm{~m}$ ). Changes in amplitude of migration and biomass observed at the end of the simulation, according to the colony size. The migration amplitude is formed by the minimum and maximum depths of migration $\left(Z_{\text {Iopt }}\right.$ : depth at which the penetrating irradiance equals the optimum irradiance for carbon fixation; $Z_{\mathrm{eu}}$ : depth of the euphotic zone; $Z_{\mathrm{m}}$ : depth of the mixing zone). Horizontal arrows cover the range of diameters that present the same periodicity of migration $(24$ or $48 \mathrm{~h})$

in the biomass peak do not receive more light energy than non-mobile phytoplankton species would experience when evenly distributed over an equivalent depth and time period: $32 \mathrm{~W} \mathrm{~m}^{-2}$ for $600 \mu \mathrm{m}$ colonies oscillating from 0 to $10 \mathrm{~m}$ under conditions of the S0 scenario. These results support Reynolds \& Walsby's (1975) conclusions, as well as observations by Ibelings et al. (1991a): under relatively stable conditions, the 

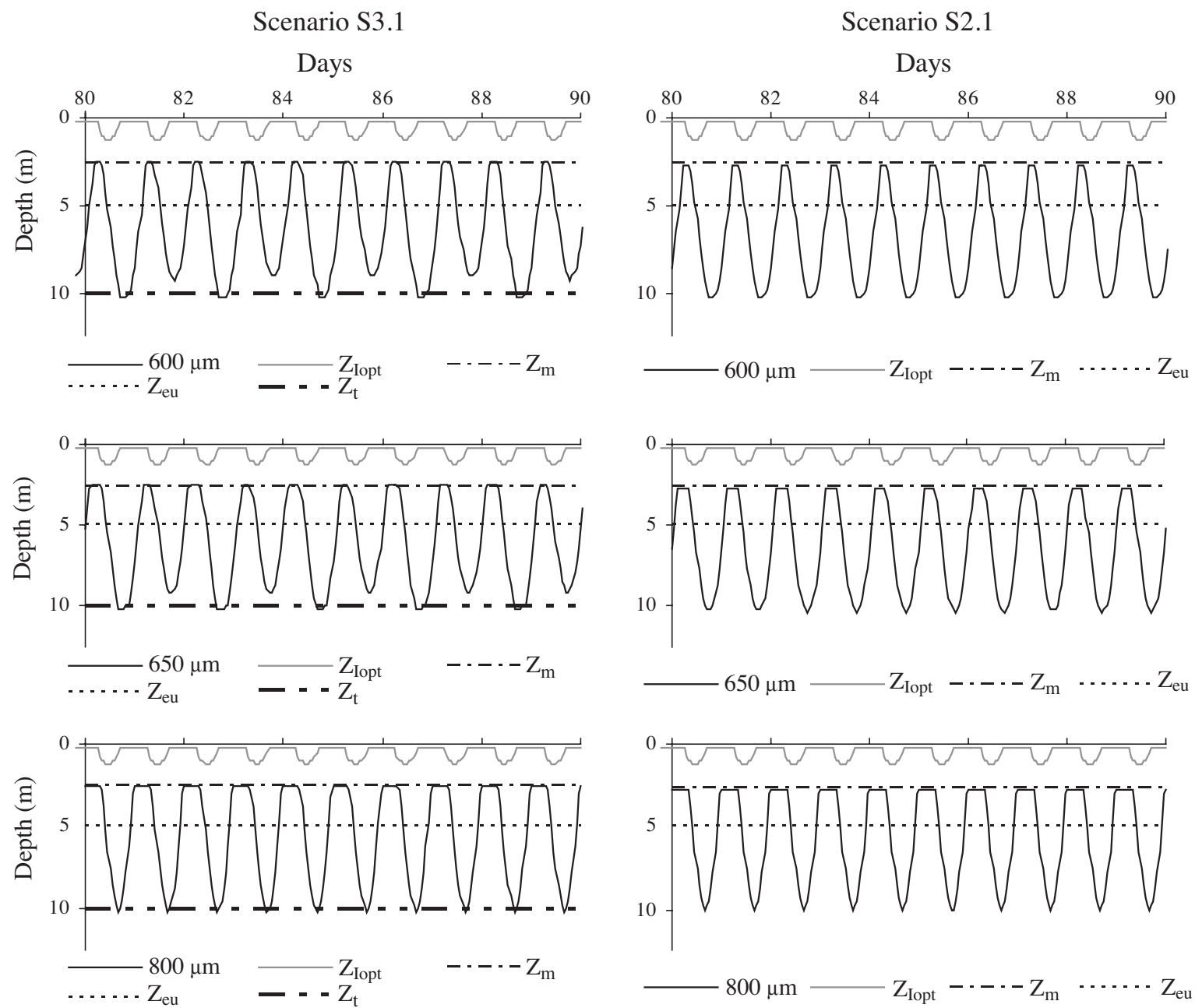

Fig. 9. Comparison of Scenarios S3.1 $\left(Z_{\mathrm{t}}=10 \mathrm{~m}, Z_{\mathrm{m}}=2.5 \mathrm{~m}\right)$ and S2.1 $\left(Z_{\mathrm{t}}=0 \mathrm{~m}, Z_{\mathrm{m}}=2.5 \mathrm{~m}\right)$. Vertical migration of 600,650 and $800 \mu \mathrm{m}$ colonies from Day 80 until Day 90. The vertical position of the biomass maximum is traced through time $\left(Z_{\text {Iopt }}\right.$ : depth at which the penetrating irradiance equals the optimum irradiance for carbon fixation; $Z_{\text {eu }}$ depth of the euphotic zone; $Z_{\mathrm{m}}$ : depth of the mixing zone; $Z_{\mathrm{t}}$ : depth of the thermocline)

buoyancy of this cyanobacterium does not give it access to higher irradiance, but enables it to reduce light fluctuations, which results in a higher growth rate.

However, stable conditions are rare in natural environments. Basically, external conditions always generate mixing, the depth of which can fluctuate quite fast during the day. The overall phytoplankton community is spread throughout this mixed layer, where it passively experiences the same amount of light. Still, Microcystis colonies can migrate out of $Z_{\mathrm{m}}$ and reach other layers, with depth depending on the diameter of the colonies. The benefit they gain from migrations to these layers then depends on the conditions they meet at certain depths (irradiance, temperature, nutrients, etc.).

\section{Combined influence of the $Z_{\mathrm{eu}}: Z_{\mathrm{m}}$ ratio and of colony diameter on biomass production}

In the case of a mixed layer, small-diameter colonies $(80 \mu \mathrm{m})$ can be considered non-mobile, since their ability to migrate is rather low. The biomass production, thus, directly depends on the light conditions provided in $Z_{\mathrm{m}}$ : optimal if $Z_{\mathrm{eu}}=Z_{\mathrm{m}}$, lower in any other case. When diameter increases, colonies become more independent of the mixing process: they can sink out of $Z_{\mathrm{m}}$ longer and deeper. Differences in this pattern result from conditions of light and temperature, but also from the velocity at which colonies sink out of $Z_{\mathrm{m}}$, i.e. from their size and their $C: M$ ratio in $Z_{\mathrm{m}}$. The return to $Z_{\mathrm{m}}$ is not dependent on the conditions of the downward migration, but on the depth at 
which the migration is reversed, on the diameter and on temperature.

When $Z_{\mathrm{m}}<Z_{\text {eu }}$, the availability of light is always high in the mixed layer. $Z_{\mathrm{m}}$ is then a zone of carbon fixation rather than of biomass production. All colonies, whatever their diameter, sink below $Z_{\mathrm{m}}$, where they form a peak and encounter conditions under which migration is effective. Only small colonies $(\varnothing<250 \mu \mathrm{m})$ take advantage of this situation in terms of produced biomass. Large-diameter colonies $(\varnothing>600 \mu \mathrm{m})$ are at a disadvantage here regarding carbon fixation because they cannot stay at the surface during the night and so do not reconstitute sufficient reserves from the rising sun before they sink.

When $Z_{\mathrm{eu}}=Z_{\mathrm{m}}$, most of the biomass is produced in $Z_{\mathrm{m}}$ as: (1) conditions of light are very favourable and (2) part of the biomass accumulates there, entrained by the mixing. Biomass production is much higher here, but decreases with increasing diameters as colonies sink out of the optimal production zone and explore layers darker than $Z_{\mathrm{m}}$. As carbon fixation is optimal in $Z_{\mathrm{m}}$, the sinking velocity out of $Z_{\mathrm{m}}$ is high (high $C: M$ ). This emphasises the effects of diameter and of delays during the return to $Z_{\mathrm{m}}$. Diameters from 80 to $500 \mu \mathrm{m}$ present the highest production rates.

When $Z_{\mathrm{m}}>Z_{\text {eu }}$ more colonies are entrained within $Z_{\mathrm{m}}$, but conditions of light are worse; photosynthesis decreases as well as carbon storage. For equivalent diameters, velocities are lower here than in the previous cases, and maximum depths reached by colonies are lower. Under these conditions, the diameter effect is less spectacular; mixing almost negates the advantage gained by migration. Indeed, Ibelings et al. (1991b), Visser et al. $(1995,1996)$ and Lilndenschmidt (1999) observed that a prolonged and deep mixing strongly reduces the chances for Microcystis to form a substantial biomass in natural environments.

In a nutshell, mixing seems to be favourable for small colonies (up to $400 \mu \mathrm{m}$ ), by allowing them to exploit a larger range of irradiances; the optimal conditions are reached when the mixing zone matches the euphotic zone. The largest diameters $(\varnothing>600 \mu \mathrm{m})$ are always at a disadvantage through mixing: these fast colonies regenerate their carbon reserves in the early morning and turbulence does not allow them to exploit the light gradient as well before they sink. We nevertheless note that the model does not take light attenuation in colonies into consideration. Thus, we may be overestimating the irradiance actually experienced by the largest colonies; as a consequence, the model may predict, for very large colonies, a shorter stay at the surface than what actually occurs in nature. However, we would not expect colonies to fix more carbon in this case, as the attenuation of light inside the colonies would compensate for the longer stay at the surface. In general, our results are similar to those obtained by Howard's (2001) simulations and by Humphries \& Lyne (1988) with a vertical physical model.

\section{Influence of thermal stratification on biomass production}

Strong seasonal stratification affects large colonies $(\varnothing>600 \mu \mathrm{m})$, the only colonies able to reach the depth of the thermal gradient. As soon as colonies cross the thermocline, the lower temperature slows down the consumption of carbon and, thus, the upward movement of colonies and their return to the surface. Growth is limited twice: directly, through the effect of temperature on biosynthesis, and indirectly, via the migration pattern, which no longer allows the optimal use of light in layers near the surface. Nevertheless, a long stay at great depths can offer other advantages, for instance better access to nutrients.

\section{Ecological advantage of a variable diameter}

The competitive advantage gained by buoyancy regulation, regarding access to nutrients, has already been widely emphasised in the literature (Reynolds et al. 1987, Konopka 1989, Kromkamp et al. 1989, Varis 1993, among others). In our simulations, in which nutrients are not represented, the model indicates the most efficient size for exploiting the light gradient. Any descent to a dark depth is registered as a disadvantage for growth, and the model reveals the highest growth efficiency in small- to medium-sized colonies. In natural environments, deeper layers are nutrient rich; thus, a gain from a nutritive point of view could compensate for the drawback represented by deep migrations to light-deficient layers. The optimal diameter is expected to be that which offers the best compromise between exploitation of light-intense layers at the surface and deeper, more nutrient-rich zones. It has been shown that this optimal diameter changes throughout the yearly cycle to ensure the best possible adaptation to the environment.

The efficiency of small- and medium-sized colonies being highest under mixed conditions gives such colonies a competitive edge within a diverse planktonic community, as the turbulent entrainment tends to equalise the growth differences between mobile and non-mobile algae. They are also able to adapt to rapid mixing fluctuations without lowering their growth yield. Moreover, their small size, which provides them with a higher surface:volume ratio, would allow them to better exploit nutrient resources (Humphries \& Lyne 
1988). These conditions are generally met during spring, when mixing and stratification alternate, building up the seasonal thermocline, and nutrients are not yet limiting. Small diameters thus seem to be the best adaptation to spring conditions.

In all configurations of mixing we analysed, large colonies tended to stay longer in deeper, nutrient-rich layers. Access to these zones is promoted by shallow mixing and is prolonged when the thermocline is established. Such conditions are particularly favourable to Microcystis in summer, especially in eutrophic waters, where the shallow euphotic zone is not easily exploited by non-mobile algae. In these highly segregated waters, organisms with the ability to carry out fast vertical movements that offer access to deep, richer layers have an advantage. Large diameters thus seem best adapted to summer conditions.

In the Grangent reservoir, the diameter increase we observed throughout spring and summer thus probably reflects an ecological adaptation of colonies to environmental fluctuations at a seasonal scale (Reynolds 1990).

\section{CONCLUSIONS}

In natural environments, phytoplankton is continuously distributed by turbulence in the vertical gradients of light and temperature. Using the Yoyo model, we analysed how different conditions of irradiance, mixing and thermal stratification influence the migration pattern and biomass production of Microcystis colonies, according to their size. Migration of Microcystis colonies is an auto-regulated system to exploit light resources more efficiently. This special feature is represented in the model through the dynamics of the metabolism of carbon reserves, due to the combined influence of photosynthesis and biosynthesis. Although the conditions of simulation are schematic, they allow identification of situations in which the ability to regulate buoyancy gives Microcystis an advantage over non-mobile phytoplankton. Even if some vertical structures appear unfavourable for the exploitation of light energy, they nevertheless present some advantages for the access to nutrients.

Whether the water body is calm or turbulent, small colonies (up to $400 \mu \mathrm{m}$ ) produce the highest biomasses, since they can remain in the light-intense surface layers. In spring, the water column progressively stratifies, with mixed and calm periods alternating. Small colonies are thus the most able to adapt to these fast fluctuations in mixing conditions, without losses to their growth yield. Within the diverse planktonic community, they are also more competitive than the large colonies, as turbulent entrainment tends to offset the differences in growth between mobile and non-mobile phototrophs.

Colonies of the largest diameters $(\varnothing>600 \mu \mathrm{m})$ produce the lowest biomasses in all situations, as their stays in light-intense layers are shorter. All the vertical structures of mixing tend to make their stay longer in deeper, nutrient-rich layers. Access to these zones is made easier by shallow mixing, and is prolonged in the presence of a thermocline. These conditions are particularly favourable to Microcystis in summer, especially in eutrophic environments, where the shallow euphotic zone is not easily exploited by non-mobile algae.

The diameter increase we observed throughout spring and summer in the Grangent reservoir thus probably reflects an ecological adaptation of colonies to the fluctuations of their environment at a seasonal scale.

Acknowledgements. This study was carried out in a joint research program of Electricite De France and the Centre d'Ecologie des Systèmes Aquatiques Continentaux (CESAC; now the Laboratoire d'Ecologie des Hydrosystèmes) of the Université Paul Sabatier, and was supported by Agence de l'Eau Loire-Bretagne. The manuscript benefited from accurate comments by an anonymous reviewer.

\section{LITERATURE CITED}

Deacon C, Walsby AE (1990) Gas vesicle formation in the dark, and in light of different irradiances, by the cyanobacterium Microcystis sp. Br Phycol J 25:133-139

Howard A (2001) Modeling movement patterns of the cyanobacterium Microcystis. Ecol Appl 11(1):304-310

Humphries SE, Lyne VD (1988) Cyanophyte blooms: the role of cell buoyancy. Limnol Oceanogr 33:79-91

Ibelings BW, Mur LR, Walsby AE (1991a) Diurnal changes in buoyancy and vertical distribution in populations of Microcystis in two shallow lakes. J Plankton Res 13(2):419-436

Ibelings BW, Mur LR, Kinsman R, Walsby AE (1991b) Microcystis changes its buoyancy in response to the average irradiance in the surface mixed layer. Arch Hydrobiol 120(4):385-401

Ibelings BW, Kroon BMA, Mur LR (1994) Acclimation of photosystem II in a cyanobacterium and a eukaryotic green alga to high and fluctuating photosynthetic photon flux densities, simulating light regimes induced by mixing in lakes. New Phytol 128:407-424

Konopka A (1989) Metalimnetic cyanobacteria in hard-water lakes: buoyancy regulation and physiological state. Limnol Oceanogr 34(7):1174-1184

Konopka AE, Klemer AR, Walsby AE, Ibelings BW (1993) Effects of macronutrients upon buoyancy regulation by metalimnetic Oscillatoria agardhii in Deming Lake, Minnesota. J Plankton Res 15(9):1019-1034

Kromkamp JC, Konopka A, Mur LR (1988) Buoyancy regulation in light-limited continuous cultures of Microcystis aeruginosa. J Plankton Res 10(2):171-183

Kromkamp J, Van den Heuvel A, Mur LR (1989) Phosphorus uptake and photosynthesis by phosphate-limited cultures of the cyanobacterium Microcystis aeruginosa. Br Phycol J 24:347-355 
Lilndenschmidt KE (1999) Controlling the growth of Microcystis using surged artificial aeration. Int Rev Hydrobiol 84(3):243-254

Parker A (1974) Empirical funtions relating metabolic processes in aquatic systems to environmental variables. J Fish Res Board Can 31:1550-1552

Peeters JCH, Eilers PHC (1978) The relationship between light intensity and photosynthesis. A simple mathematical model. Hydrobiol Bull 12:134-136

Post AF, De Wit R, Mur LR (1985) Interactions between temperature and light intensity on growth and photosynthesis of the cyanobacterium Oscillatoria agardhii. J Plankton Res 7(4):487-495

Rabouille S, Thébault JM, Salençon MJ (2003) Simulation of carbon reserve dynamics in Microcystis and its influence on vertical migration with Yoyo model. CR Biol 326(4): 349-361

Rabouille S, Salençon MJ, Thébault JM (2005) Functional analysis of Microcystis vertical migration: a dynamic model as a prospecting tool. I. Processes analysis. Ecol Model (in press)

Reynolds CS (1990) Temporal scales of variability in pelagic environments and the response of phytoplankton. Freshw Biol 23:25-53

Reynolds CS, Rogers DA (1976) Seasonal variations in the vertical distribution and buoyancy of Microcystis aeruginosa Kütz. Emend. Elenkin in Rostherne Mere, England. Hydrobiologia 48:17-23

Reynolds CS, Walsby AE (1975) Water-blooms. Biol Rev 50: 437-481

Reynolds CS, Oliver RL, Walsby AE (1987) Cyanobacterial dominance: the role of buoyancy regulation in dynamic lake environments. NZ J Mar Freshw Res 21(3): $379-390$

Editorial responsibility: Frede Thingstad, Bergen, Norway
Rücker J, Kohl JG (1994) Indication of growth-limiting factors of planktonic cyanobacteria by application of microscopephotometry. Verh Int Verein Limnol 25:2218-2220

Salençon MJ, Thébault JM (1997) Modélisation d'écosystème lacustre. Application à la retenue de Pareloup (Aveyron). Masson, Paris

Spigel RH, Imberger J (1987). Mixing processes relevant to phytoplankton dynamics in lakes. NZ J Mar Freshw Res 21(3):361-377

Thomas RH, Walsby AE (1985) Buoyancy regulation in a strain of Microcystis. J Gen Microbiol 131:799-809

Thomas RH, Walsby AE (1986) The effect of temperature on recovery of buoyancy by Microcystis. J Gen Microbiol 132: 1665-1672

Van Rijn J, Shilo M (1985) Carbohydrate fluctuations, gas vacuolation, and vertical migration of a scum-forming cyanobacteria in fishponds. Limnol Oceanogr 30: $1219-1228$

Varis O (1993) Cyanobacteria dynamics in a restored Finnish lake: a long term simulation study. Hydrobiologia 268: 129-145

Visser PM (1995) Growth and vertical movement of the cyanobacterium Microcystis in stable and artificially mixed water colums. PhD thesis, University of Amsterdam

Visser PM, Ketelaars HAM, Mur LR (1995) Reduced growth of the cyanobacterium Microcystis in an artificially mixed lake and reservoir. Water Sci Technol 32 (4):53-54

Visser PM, Ibelings BW, Van der Veer B, Koedood J, Mur LR (1996) Artificial mixing prevents nuisance blooms of the cyanobacterium Microcystis in Lake Nieuwe Meer, the Netherlands. Freshw Biol 36 (2):435-450

Visser PM, Passarge J, Mur LR (1997) Modelling vertical migration of the cyanobacterium Microcystis. Hydrobiologia 349:99-109

Submitted: August 18, 2004; Accepted: March 25, 2005

Proofs received from author(s): June 10, 2005 